\title{
Luminescent Properties of Europium Complexes with Different Long Chains in Langmuir-Blodgett (LB) Films
}

\author{
Tiesheng Li ${ }^{1,2}$, Wei Shang ${ }^{3}$, Fuli Zhang ${ }^{1,2}$, Luyuan $\mathrm{Mao}^{3}$, Caiqin Tang ${ }^{1,2}$, \\ Maoping Song ${ }^{1}$, Chenxia Du ${ }^{1,2}$, Yangjie $\mathrm{Wu}^{1,2}$ \\ ${ }^{1}$ Department of Chemistry, Henan Key Laboratory of Chemical Biology and Organic Chemistry, The Key and \\ Open Lab of Applicated Chemistry of Zhengzhou Universities, Zhengzhou, China \\ ${ }^{2}$ Key Lab of Advanced Information Nano-Materials of Zhengzhou, Zhengzhou University, Zhengzhou, China \\ ${ }^{3}$ Institute of Materials and Engineering, Zhengzhou University, Zhengzhou, China \\ E-mail: lts34@zzu.edu.cn \\ Received July 12, 2010; revised September 1, 2010; accepted March 11, 2011
}

\begin{abstract}
A series of europium(III) complexes with different chain length, tris [2-m-pyridylmethanamido-5-phenyl$(1,3,4)$-oxadiazole] mono [2-(4-n-alkylphenyl)-iminazole (4,5-f)-1,10-phenanthroline] $\mathrm{Eu}(\mathrm{III})$ [Eu(PMA) ${ }_{3} \mathrm{~N}_{\mathrm{n}}$ $(\mathrm{n}=6,10,14,18)]$ were synthesized. All of these amphiphilic europium(III) complexes could form stable Langmuir film at air/water interface and could be transferred onto hydrophilic quartz and mica substrates by measurement of UV spectra in which the absorbance of the LB films at about $288 \mathrm{~nm}$ scales showed the linearity with the number of layers deposited. In order to investigate relation between fluorescence properties and the arrangement of molecular in LB films, surface topography of monolayer films were observed by atomic force microscopy (AFM). Results showed that the emission spectra have Eu(III) characteristic peaks and strong emission strength. It is interesting that the molecular with looser arrangement in LB films has better monochromacity, which illustrated that energy might transferred more easily from ligand to Eu(III) in loosen structure films.
\end{abstract}

Keywords: Europium Complex, LB Films, Photo-Luminescence, AFM

\section{Introduction}

The luminescent behaviors of lanthanide complexes have been widely studied due to their sharp line and long life emission, which are caused by an inter- and/or intramolecular energy transfer from the ligands to the metal ions followed by luminescence emission [1,2]. Eu(III) complexes can give strong characteristic lumenescence with long lifetime and excellent monochromacity, so they were regarded as one of the best luminescence materials and were widely used in chemistry, physics, biochemistry and agriculture, optical amplification and waveguide, laser materials [3], OLED [4,5], Luminescent Chemical Sensors [6]. The lumenescent lanthanide complexes can be embedded in sol-gel glasses, LB films, and polymer film with the latter matrix being the preferred one [7]. Much attention has recently been attracted to the assembling of the lanthanide complexes by physical and chemical methods. Some ways based on Langmuir Blodgett (LB) films have been used to deposit many lan- thanide complexes as ordered and ultrathin films. LB technique has been recognized as one of the most powerful tools of making thin films with highly ordered structure [8], which can be used to investigate the interaction and orientation among molecules in films, as well as molecular assembly and making device. Since LB technique was introduced to fabricate $\mathrm{Eu}(\mathrm{III})$ complexes films [9], many researches have been done to study their luminescence of other materials with $\mathrm{Eu}(\mathrm{III})$ complexes composition [10]. As hydrophilic ability of Eu(III) complexes was strong and were hard to form stable film on subphase, ways were done to overcome $\mathrm{Eu}(\mathrm{III}) \mathrm{com}$ plexes LB films stability and weak emission strength in films [6-9,11-13]. Mixture system containing complexes and classical film-forming molecules (SA or AA) could form stable Langmuir film at air/water surface and could be fabricated excellent LB films, but film-forming molecules affected emission strength because they were hard to be controlled exact molecular packing in films $[14,15]$. To solve this problem, some researchers tried to utilize 
mixed subphase and got better emission spectra, but this method was complexity and the cost was expensive [16]. Thin films of lanthanide-containing polyoxometalates have been prepared by several methods, including via LB technique, [17-19]. Meanwhile, C. H. Huang et al. investigated amphiphilic Eu(III) complexes LB films without film former also showing characteristic $\mathrm{Eu}(\mathrm{III})$ emission strength [20]. Mitsuishi, M studied the LB films consisted of a mixture of poly ( $N$-dodecyla-crylamide) and $[E u(t t a) 3(p h e n)]$ sandwiched between poly $(N$-do decylacrylamide) layers which were used as optical temperature sensor [21]. Qian et al., studied the monolayer assemblies of some samarium, europium, and terbium complexes with the $\hat{a}$-diketonate ligand thienyltrifluoroacetone and concluded that the closely packed structures of the complexes have some influences on the emissions of the lanthanoid ions, especially for the europium and samarium complexes [22,15]. However, the relationship between the emission strength and the orientation topography were not deeply studied in the researches done above. It is known that the structure and orientation of europium complexes in film can strongly affect their fluorescence properties of europium complexes. Herein, Novel amphiphilic Eu(III) complexes with symmetrical ligand and coligands with different long alkyl chain were synthesized and their LB films were fabricated without other film former in order to investigate the inference of different chains on their relationship between surface topography in films and fluorescence properties.

\section{Experimental}

In our design of Eu complex, we mainly consider that the type and number of ligands in the complex and the properties of filming. That is to say, one is the ligands that not classical diketonate, but asymmetry one having in- dole group which can co-ordinated with $\mathrm{Eu}$ ion and one coligand which have excellent film forming properties through modifying with alky chain because of it being easily substituted by alkyl chains. Since the alkyl chains create a hydrophobic microenvironment, which protects the $\mathrm{Eu}^{3+}$ ion from hydroxyl groups and the alkyl chains is easier to prepare without cracks $[23,24]$. Moreover, the long alkyl chain stabilizes the amorphous phase. It is known that crystallization of the emissive layer has an unfavorable effect on the electro-Luminescence [25], which resulted in an effective intermolecular energy transfer and a high sensitization efficiency [26]. $\mathrm{Eu}(\mathrm{PMA})_{3} \mathrm{~N}_{\mathrm{n}}$ $(\mathrm{n}=18,14,10,6)$ were synthesized according to the literature procedure [27-30]. Their structures were shown in Figure 1.

Synthesis of 2-(4-octadecylalk-oxyphenyl)-iminazole (4,5-f)-1, 10-Phenanthroline $\left(\mathrm{N}_{18}\right)$ 1,10-phenanthroline5,6 diketone, $0741 \mathrm{oz}$ and $3.0 \mathrm{~g} \mathrm{NH}_{4} \mathrm{OAC}$ were dispersed into $30 \mathrm{ml}$ glacial acetic acid, and heated, then $2.34 \mathrm{~g}$ 4-octadecyalkoxyphenyl aldehyde dropped into $10 \mathrm{ml}$ glacial acetic acid and circumfluenced for 3 hours. Cooling to the room temperature and washed by $200 \mathrm{ml}$ water, neutralized by aqueous ammonia to $\mathrm{pH}=7 \sim 8$, yellow sediment was filtrated, washed by water and recrystallized in chloroform/ethanol (1:5), vacuum dried and yellow solid $3.1 \mathrm{~g}$ was got, yield 77\%. ${ }^{1} \mathrm{HNMR}$ $\left(\mathrm{CDCl}_{3}\right), \delta(\mathrm{ppm}): 0.848-0.881(\mathrm{t}, 3 \mathrm{H}), 1.237-1.284(\mathrm{t}$, $28 \mathrm{H}), 1.325-1.377(\mathrm{q}, 2 \mathrm{H}), 1.662-1.698(\mathrm{t}, 2 \mathrm{H}), 3.815-$ 3.848 (t, 2H), 6.741-6.762 (d, 2H), 7.374 (s, 2H), 8.2518.272 (d, 2H), 8.769 (s, 2H), 8.904-8.922 (d, 2H).

$\mathrm{N}_{6}: \mathrm{C}_{25} \mathrm{H}_{24} \mathrm{~N}_{4} \mathrm{O}, \mathrm{FW}=396.5$, yield: $39 \%$. ${ }^{1} \mathrm{HNMR}$ $\left(\mathrm{CDCl}_{3}\right), \delta(\mathrm{ppm}): 0.841-0.875(\mathrm{t}, 3 \mathrm{H}), 1.258-1.293(\mathrm{q}$, $4 \mathrm{H}), 1.345-1.414(\mathrm{~m}, 2 \mathrm{H}), 1.665-10735$ (m, 2H), 3.843$3.876(\mathrm{t}, 2 \mathrm{H}), 6.772-6.793(\mathrm{~d}, 2 \mathrm{H}), 7.414(\mathrm{~s}, 2 \mathrm{H}), 8.221-$ $8.243(\mathrm{~d}, 2 \mathrm{H}), 8.818-8.867(\mathrm{~d}, 4 \mathrm{H})$.

$\mathrm{N}_{10}: \mathrm{C}_{29} \mathrm{H}_{32} \mathrm{~N}_{4} \mathrm{O}, \mathrm{FW}=452.6$, yield: $73 \%$. ${ }^{1} \mathrm{HNMR}$ $\left(\mathrm{CDCl}_{3}\right), \delta(\mathrm{ppm}): 0.831-0.864(\mathrm{t}, 3 \mathrm{H}), 1.223-1.264(\mathrm{~d}$,

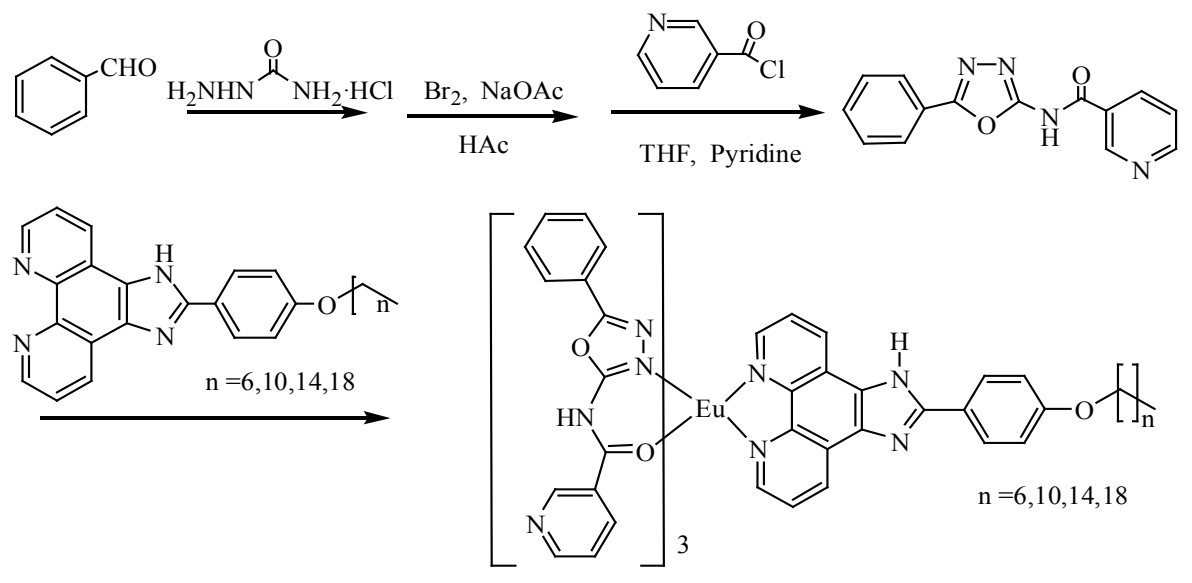

Figure 1. Structure of amphiphilic Eu(III) complexes. 
$12 \mathrm{H}), 1.308-1.345(\mathrm{t}, 2 \mathrm{H}), 1.632-1.702(\mathrm{~m}, 2 \mathrm{H}), 3.790-$ $3.822(\mathrm{t}, 2 \mathrm{H}), 6.720-6.741(\mathrm{~d}, 2 \mathrm{H}), 7.360(\mathrm{~s}, 2 \mathrm{H}), 8.221-$ $8.242(\mathrm{~d}, 2 \mathrm{H}), 8.762-8.770(\mathrm{~d}, 2 \mathrm{H}), 8.893-8.912(\mathrm{~d}, 2 \mathrm{H})$.

$\mathrm{N}_{14}: \mathrm{C}_{33} \mathrm{H}_{40} \mathrm{~N}_{4} \mathrm{O}, \mathrm{FW}=508.7$, yield: $51 \%$. ${ }^{1} \mathrm{HNMR}$ $\left(\mathrm{CDCl}_{3}\right), \delta(\mathrm{ppm}): 0.842-0.876(\mathrm{t}, 3 \mathrm{H}), 1.226(\mathrm{~s}, 20 \mathrm{H})$, $1.278-1.350(\mathrm{~m}, 2 \mathrm{H}), 1.654-1.690(\mathrm{t}, 2 \mathrm{H}), 3.800-3.832(\mathrm{t}$, $2 \mathrm{H}), 6.724-6.745(\mathrm{~d}, 2 \mathrm{H}), 7.373(\mathrm{~s}, 2 \mathrm{H}), 8.250-8.271$ (d, $2 \mathrm{H}), 8.766(\mathrm{~s}, 2 \mathrm{H}), 8.905$ (s, 2H).

Synthesis of 2-m-pyridylmeth-anamido-5-phenyl-(1,3, 4)-oxadiazole (PMA) $0.025 \mathrm{~mol} \mathrm{~m}$-pyridylmethenyl-chlo-

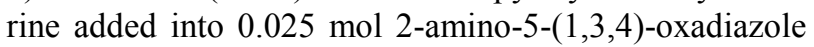
(dissolved in pyridine and tetrahydrofuran) by stirring for 2 hours at $60^{\circ} \mathrm{C}$ in water bath and sediment was filtrated, washed by water and recrystallized in ethanol, vacuum dried and white crystal was got, yield $60 \% . \mathrm{C}_{14} \mathrm{H}_{9} \mathrm{~N}_{2} \mathrm{O}_{2}$, $\mathrm{FW}=266.3 .{ }^{1} \mathrm{HNMR}\left(\mathrm{CDCl}_{3}\right), \delta(\mathrm{ppm}): 7.508$ - $7.602(\mathrm{~m}$, $4 \mathrm{H}), 8.060-8.078(\mathrm{~d}, 2 \mathrm{H}), 8.599-8.618(\mathrm{~d}, 2 \mathrm{H}), 8.836$ (s, 1H), 9.500 (s, 1H).

Synthesis of $\mathrm{Eu}(\mathrm{PMA})_{3} \mathrm{~N}_{18} 3 \mathrm{ml} \mathrm{EuCl}_{3}$ (dissolve in methanol) was dropped into $0.24 \mathrm{~g}$ PMA (dissolved in 20 $\mathrm{ml}$ ethanol, heated) and cooled to the room temperature, $\mathrm{MeONa} / \mathrm{MeOH}$ was used to accommodate $\mathrm{pH}=7$, then dropped $\mathrm{N}_{18}$ into ethanol boiling for 0.5 hour. Cooling to the room temperature, $0.34 \mathrm{~g}$ yellow solid was got by filtrated, washed and vacuum dried. Yield: $84 \%$.

IR (KBr): $\mathrm{Eu}\left(\mathrm{PMA}_{3} \mathrm{~N}_{6}: 3055\right.$ (Ar-H); 2929 (C-H); $2858\left(\mathrm{CH}_{2}\right) ; 1588$ (phen:C=N); $1539(\mathrm{C}-\mathrm{C}) ; 1253$ (Ar-O); 764 (C-H).

$\mathrm{Eu}(\mathrm{PMA})_{3} \mathrm{~N}_{10}: 3061(\mathrm{Ar}-\mathrm{H}) ; 2925(\mathrm{C}-\mathrm{H}) ; 2853\left(\mathrm{CH}_{2}\right)$; 1588 (phonic=N); 1539 (C-C); 1251 (Ar-O); $763(\mathrm{C}-\mathrm{H})$.

$\mathrm{Eu}(\mathrm{PMA})_{3} \mathrm{~N}_{14}$ : $3055(\mathrm{Ar}-\mathrm{H}) ; 2924(\mathrm{C}-\mathrm{H}) ; 2852\left(\mathrm{CH}_{2}\right)$; 1588 (phonic=N); 1539 (C-C); $1252($ Ar-O); $763(\mathrm{C}-\mathrm{H})$.

$\mathrm{Eu}(\mathrm{PMA})_{3} \mathrm{~N}_{18}: 3058(\mathrm{Ar}-\mathrm{H}) ; 2924(\mathrm{C}-\mathrm{H}) ; 2852\left(\mathrm{CH}_{2}\right)$; $1588($ phonic $=\mathrm{N}) ; 1539(\mathrm{C}-\mathrm{C}) ; 1252(\mathrm{Ar}-\mathrm{O}) ; 764(\mathrm{C}-\mathrm{H})$.

\subsection{LB Films Preparation}

A chloroform solution $\left(1 \times 10^{-3} \mathrm{~mol} / \mathrm{L}\right)$ of the $\mathrm{Eu}(\mathrm{TTA})_{3}$ $\mathrm{N}_{\mathrm{n}}(\mathrm{n}=18,10,14,6)$ complexes were spread onto Langmuir trough with subphase of Millipore water (18 M $\mathrm{M}$ $\mathrm{cm}^{-1}$ ) and were left for $20 \mathrm{~min}$ for the solvent evaporation. The surface pressure-area isotherms ( $\pi-A$ isotherms) were recorded at a barrier compression rate of $10 \mathrm{~mm} /$ min. Multilayer LB films were deposited onto hydrophilic quartz substrate in a Z-type at a rate of $5 \mathrm{~mm} / \mathrm{min}$ at $20\left( \pm 0.5^{\circ} \mathrm{C}\right)$.

\subsection{Luminescence Quantum Yields}

The luminescence quantum yields of europium complexes were determined by comparison with standard quinine sulfate as reference in degas tetrhydrofuran solution [31]. The sample was dissolved in tetrhydrofuran. The concentration of all solution is $2 \times 10^{-6} \mathrm{~mol} \cdot \mathrm{L}^{-1}$. The equation used for calculating luminescence quantum yields $\left(\Phi_{f x}\right)$ was

$$
\Phi_{f x}=\frac{n_{x}^{2}}{n_{s t d}^{2}} \cdot \frac{F_{x}}{F_{s t d}} \cdot \Phi_{f s t d},
$$

where $F$ denote the integrated area of the emission spectra, $n$ is diffraction index, $x$ is number of Eu complexes, $f$ is fluorescence, std is standard quinine sulfate as reference and $\Phi_{f s t d}=0.55$. The values of $\Phi_{f x}$ were listed in Table 1. The lifetimes (Table 1) of europium complexes were measured in solid state with HORIBA JOBIN YVON FluoroMax-P.

\subsection{Spectroscopy Measurement}

Measurement of $\pi$-A isotherms was carried out with Langmuir trough system (KSV5000-3). Ultraviolet spectra were obtained with a PerkinElmer Lambda 35 spectrophotometer. Fluorescence spectra were recorded on a HORIBA JOBIN YVON FluoroMax-P fluorescence spectrophotometer. AFM pictures were observed on apparatus (SPM-9500 J3). Film thickness was measured by nkd - 8000 v Thin Film Measurement Instrument.

\section{Results and Discussion}

\subsection{Monolayer Behavior at the Air/Water Surface}

The $\pi-\mathrm{A}$ isotherms of four Eu complexes were shown in Figure 2. It showed that four europium complexes have a steep rise from surface pressure range and fairly high collapse pressure, indicating that stable condensed monolayer could be formed at air/water interface. The average limiting surface area $\mathrm{A}_{0}$ (by extrapolating the linear portion of the condensed state to zero surface pressure) were listed in Table 2 and surface areas were almost not changed regularly with alkyl chain changed (Table 2), indicating that the molecular areas of these complexes in the monolayers corresponded to their closely packed large head groups [15]. Among of these complexes, molecular area of the complex $\operatorname{Eu}(\mathrm{PMA})_{3} \mathrm{~N}_{18}$ was

Table 1. Luminescence quantum yields data $\phi$.

\begin{tabular}{ccccc}
\hline Comple & $\lambda \operatorname{ex}(\mathrm{nm})$ & $\lambda \operatorname{em}(\mathrm{nm})$ & $\Phi^{\mathrm{a}}(\%)$ & Life time $^{\mathrm{b}} / \mathrm{m}$ \\
\hline Eu(PMA) ${ }_{3} \mathrm{~N}_{18}$ & 356 & 612 & 2.6 & 1.82 \\
Eu(PMA) ${ }_{3} \mathrm{~N}_{14}$ & 356 & 612 & 3.1 & 2.00 \\
Eu(PMA) ${ }_{3} \mathrm{~N}_{10}$ & 356 & 612 & 3.2 & 1.92 \\
Eu(PMA) $)_{3} \mathrm{~N}_{6}$ & 356 & 612 & 4.1 & 1.83 \\
\hline
\end{tabular}

${ }^{\mathrm{a}}$ In tetrhydrofuran solution (Concentration: $2 \times 10^{-6} \mathrm{molL}^{-1}$ ). 


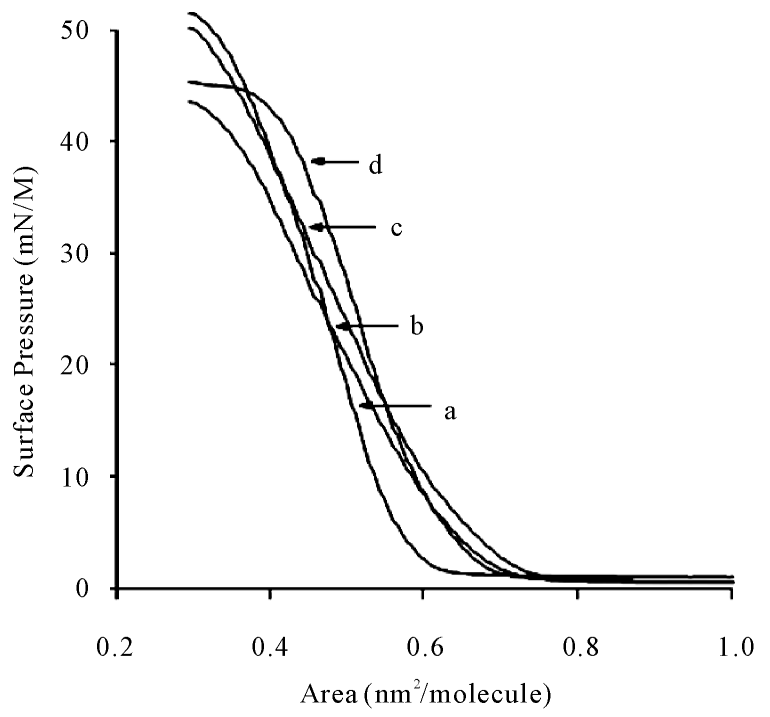

Figure 2. The $\pi-A$ isotherms of europium complexes. (a) $\operatorname{Eu}(\operatorname{PMA})_{3} \mathrm{~N}_{18} ;$ (b) $\operatorname{Eu}(\operatorname{PMA})_{3} \mathrm{~N}_{14} ;$ (c) $\operatorname{Eu}(\operatorname{PMA})_{3} \mathrm{~N}_{10} ;$ (d) Eu $(\mathbf{P M A})_{3} \mathbf{N}_{6}$.

Table 2. Complex data at air/water interface.

\begin{tabular}{ccc}
\hline Number & $\mathrm{A}_{0} / \mathrm{nm}^{2}$ & Collapse pressure $(\mathrm{mN} / \mathrm{m})$ \\
\hline a & 0.58 & 42 \\
b & 0.65 & 47 \\
c & 0.62 & 40 \\
d & 0.63 & 42 \\
\hline
\end{tabular}

about $0.58 \mathrm{~A}_{0} / \mathrm{nm}^{2}$ which is the smallest, which seems to be dominated by its longer chain in addition to the packed head group. These results reflect the effect of the structure of the molecules on their monolayer behaviors due to the large hydrophilic head group and long chains.

The data of monolayer LB film thickness measured with nkd $-8000 \mathrm{v}$ Thin Film Measurement Instrument and simulated theory molecule height were presented in Table 3, and then incline angle $\theta$ of molecule toward the substrate was calculated. According to the date of Tables 2, 3, the arrangement of the europium complexes were presumed that the part of ligands (PAM) and $\mathrm{N}_{6,10,14,18}$ coordinated with $\mathrm{Eu}^{3+}$ laid on horizontal direction on the water surface and the alkyl chains have certain orientation shown in Scheme 1.

\subsection{LB Films Formation}

The predominant feature of the UVspectra of the complexes under this investigation is the strong band occurring from 280 to $380 \mathrm{~nm}$ due to the $\pi-\pi^{*}$ type transition of the ligands associated with the conjugated transitions.
Table 3. Molecular arranging function in LB films.

\begin{tabular}{cccc}
\hline Complexes & $\begin{array}{c}\text { Theoretical } \\
\text { height } / \mathrm{nm}\end{array}$ & $\begin{array}{c}\text { Monolayer } \\
\text { thickness } / \mathrm{nm}\end{array}$ & $\begin{array}{c}\text { Included } \\
\text { angle } \theta\end{array}$ \\
\hline $\mathrm{Eu}(\mathrm{PMA})_{3} \mathrm{~N}_{18}$ & 3.30 & 1.95 & 36.2 \\
$\mathrm{Eu}(\mathrm{PMA})_{3} \mathrm{~N}_{14}$ & 3.10 & 1.61 & 31.2 \\
$\mathrm{Eu}(\mathrm{PMA})_{3} \mathrm{~N}_{10}$ & 2.90 & 1.09 & 22.1 \\
$\mathrm{Eu}(\mathrm{PMA})_{3} \mathrm{~N}_{6}$ & 2.70 & 1.16 & 25.4 \\
\hline
\end{tabular}

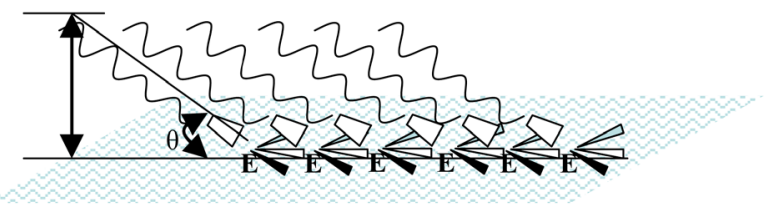

Scheme 1. Presumed arrangment of europium complexes on the water surface.

As an example, $\mathrm{Eu}(\mathrm{PMA})_{3} \mathrm{~N}_{18}$ complexes absorptions in chloroform and in LB films were measured shown in Figure 3. Comparison of $\mathrm{Eu}(\mathrm{PMA})_{3} \mathrm{~N}_{18}$ complex in $\mathrm{LB}$ films and in chloroform (Figure 3). Blue shift by $8 \mathrm{~nm}$ in LB films was observed compareing to the chloroform solution, which indicated that $\mathrm{H}$ aggregation was formed in LB films. The main peak of complex was at $287 \mathrm{~nm}$ in LB films attributed to super conjugated interaction and to $\pi-\pi^{*}$ electronic transfer of conjugated double bond of ligands. It was obvious that the distance of molecular in europium was shorter than that in chloroform, which resulted in stronger molecule interaction. Ligands were also packing orderly in LB films and played a great role in UV absorption. The similar results were also obtained for $\mathrm{Eu}(\mathrm{PAM})_{3} \mathrm{~N}_{6}, \mathrm{Eu}(\mathrm{PAM})_{3} \mathrm{~N}_{10}$ and $\mathrm{Eu}(\mathrm{PAM})_{3} \mathrm{~N}_{14}$.

Depositions of the monolayers of europium complexes are mainly dependent on both the ligands and long chains. It is known that when using the same hydrophilicity for the head groups of the complexes, the film forming ability increased with increasing the length of chain. The traditional LB method is very useful for assembling $\mathrm{Eu}(\mathrm{PMA})_{3} \mathrm{~N}_{\mathrm{n}}$ with stronger hydrophilicity and hydrophobicity as multilayers, which may relate to the stronger interactions between two layers. For example, seen from the UV-vis spectra of multilayer europium complexes, for example (Figure 4), when the number of deposited layers increased, the absorption increased. Meanwhile, the absorbance at $288 \mathrm{~nm}$ of europium complexes is proportional to the number of layers deposited (inserted in Figure 4). The linearity indicated that the $\mathrm{Eu}$ (PMA) ${ }_{3} \mathrm{~N}_{18}$ Langmuir film could be transferred onto the substrate successfully forming regular multilayers. Other complexes showed the similar results for $\mathrm{Eu}(\mathrm{PAM})_{3} \mathrm{~N}_{6}$, $\mathrm{Eu}(\mathrm{PAM})_{3} \mathrm{~N}_{10}$ and $\mathrm{Eu}(\mathrm{PAM})_{3} \mathrm{~N}_{14}$. 


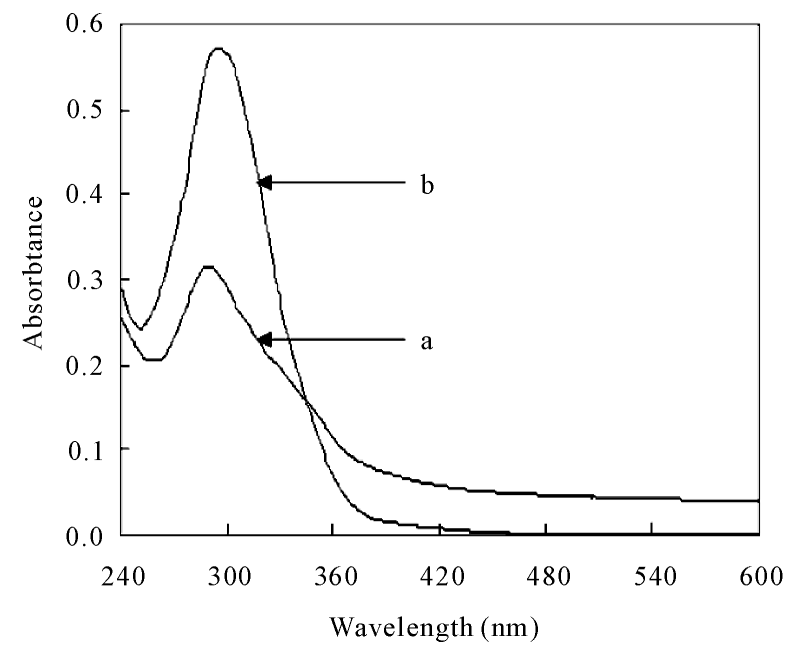

Figure 3. UV spectra of $\operatorname{Eu}(P M A)_{3} N_{18}$ in $L B$ films (a) and in chloroform (b).

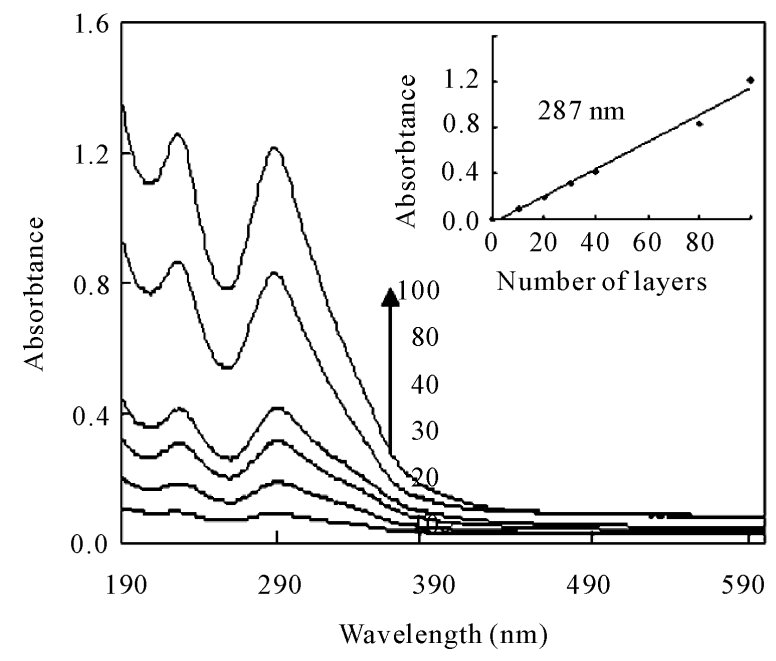

Figure 4. UV-vis spectra of multilayer LB films of $\mathrm{Eu}(\mathrm{PMA})_{3}$ $\mathbf{N}_{18}$.

\subsection{Fluorescence Spectra}

The emission spectra of all the multilayer europium complex LB films were measured. We could observe that all of them could give strong emission intensety. Emission spectra for 100-layer LB films of $\mathrm{Eu}(\mathrm{PAM})_{3} \mathrm{~N}_{18}$ 1), $\mathrm{Eu}$ $(\mathrm{PAM})_{3} \mathrm{~N}_{14}$ 2), $\mathrm{Eu}(\mathrm{PAM})_{3} \mathrm{~N}_{10}$ 3) and $\left.\mathrm{Eu}(\mathrm{PAM})_{3} \mathrm{~N}_{6} 4\right)$ were obtained shown in Figure 5. The emission spectra of $\mathrm{Eu}(\mathrm{PAM})_{3} \mathrm{~N}_{\mathrm{n}}(\mathrm{n}=18,14,10,6)$ of 100 -layer LB films $(\lambda \mathrm{ex}=372) \mathrm{nm})$ gave evident $\mathrm{Eu}(\mathrm{III})$ characteristic peaks at 582, 591, 612 and assignable to ${ }^{5} \mathrm{D}_{0} \rightarrow{ }^{7} \mathrm{~F}_{\mathrm{j}}(\mathrm{j}=0-2)$, respectively, in which hypersensitive emission $(j=2)$ is expected to be more sensitive to the ionic environment in terms of shifts in peak position as well as the relative intensity.

The hypersensitive ${ }^{5} \mathrm{D}_{0}-{ }^{7} \mathrm{~F}_{2}$ transition is predominant in these complexes, indicating that $\mathrm{Eu}^{3+}$ may lie in symmetry sites without inversion center [32]. Influenced by strong frequency doubling peak $(\lambda \mathrm{em}=612 \mathrm{~nm})$, the excitation spectrum was not obvious before $350 \mathrm{~nm}$ (not shown here). Monochromacity factor was shown in Table 4 for an intensity ratio of ${ }^{5} \mathrm{D}_{0} \rightarrow{ }^{7} \mathrm{~F}_{2}$ to ${ }^{5} \mathrm{D}_{0} \rightarrow{ }^{7} \mathrm{~F}_{1}$ emission. The value of $\mathrm{Eu}(\mathrm{PAM})_{3} \mathrm{~N}_{18}$ was lower than that of other complexes, which might be influenced by coordinate environment changing in LB films and molecules were packing tightly, which resulted in local symmetry of $\mathrm{Eu}(\mathrm{III})$ centre ion increased in LB films.

Generally, monochromacity factor of $\mathrm{Eu}(\mathrm{PAM})_{3} \mathrm{~N}_{6}$ and $\mathrm{Eu}(\mathrm{PAM})_{3} \mathrm{~N}_{10}$ were better, while monochromacity factor of $\mathrm{Eu}(\mathrm{PAM})_{3} \mathrm{~N}_{14}$ and $\mathrm{Eu}(\mathrm{PAM})_{3} \mathrm{~N}_{18}$ were lower. It was considered as molecular packing neatly for $\mathrm{Eu}(\mathrm{PAM})_{3} \mathrm{~N}_{14}$ and $\mathrm{Eu}(\mathrm{PAM})_{3} \mathrm{~N}_{18}$ in LB films and a small part of energy was bound. So it might, to some extent, inhibit energy to transfer from ligands to center ion. More explanation would be given by AFM analysis.

Another important result of this study is the influences of the asymmetry of PMA ligands on the emissions of the complexes. It is found that the emission of ${ }^{5} \mathrm{D}_{0}{ }^{-7} \mathrm{~F}_{0}$ and ${ }^{5} \mathrm{D}_{0}-{ }^{7} \mathrm{~F}_{2}$ are not splitting which occurs in other studies [33].

Considering that ${ }^{5} \mathrm{D}_{0^{-}}{ }^{7} \mathrm{~F}_{0}$ is strictly forbidden in a regular octahedral field, the emission from ${ }^{5} \mathrm{D}_{0}{ }^{-} \mathrm{F}_{0}$ in $\mathrm{LB}$ films suggests the influence of the closely packed structure on the asymmetry of the ligands surrounding the metal ions. The differences in the emission spectra for these complexes in LB films suggest that the emissions of the complexes with asymmetrically substituted ligands are little influenced by co-ligand with different length chains.

\subsection{Energy Transfer between PAM and Europium(III)}

In an effort to demonstrate the energy transfer process, the phosphorescence spectra of the complexes $\mathrm{Gd}(\mathrm{PAM})_{3}$ $\left(\mathrm{H}_{2} \mathrm{O}\right)_{2}$ was measured at $77 \mathrm{~K}$ for triplet energy level data of the ligand PAM. Since the lowest excited state ${ }^{6} \mathrm{P}_{7 / 2}$ of Gd(III) ion is too high to accept energy from a ligand, the data obtained from the phosphorescence spectra of the complexes actually reveal the triplet energy level of the corresponding ligand [34]. The triplet state energy $\left({ }^{3} \pi \pi^{*}\right)$ levels of PAM based on our measurement was found to be $20200 \mathrm{~cm}^{-1}(495 \mathrm{~nm})$. The triplet energy $\left({ }^{1} \pi \pi^{*}\right)$ levels of DBM (20 $\left.520 \mathrm{~cm}^{-1}\right)$, bpy $\left(22900 \mathrm{~cm}^{-1}\right)$ and phen $\left(22100 \mathrm{~cm}^{-1}\right)$ were taken from the literatures $[35,36]$.

Generally, the sensitization pathway in luminescent europium complexes consists of the excitation of the ligands from the ground state to their excited singlet 


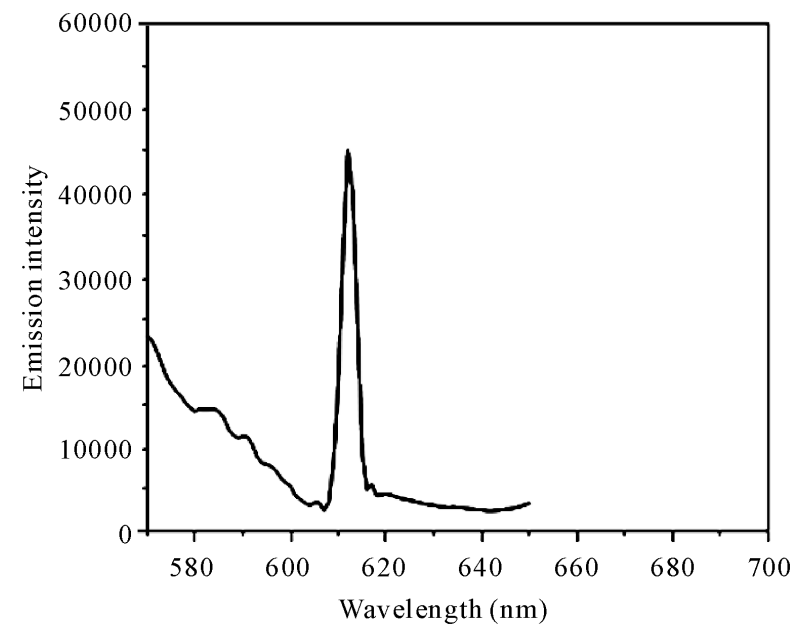

(a)

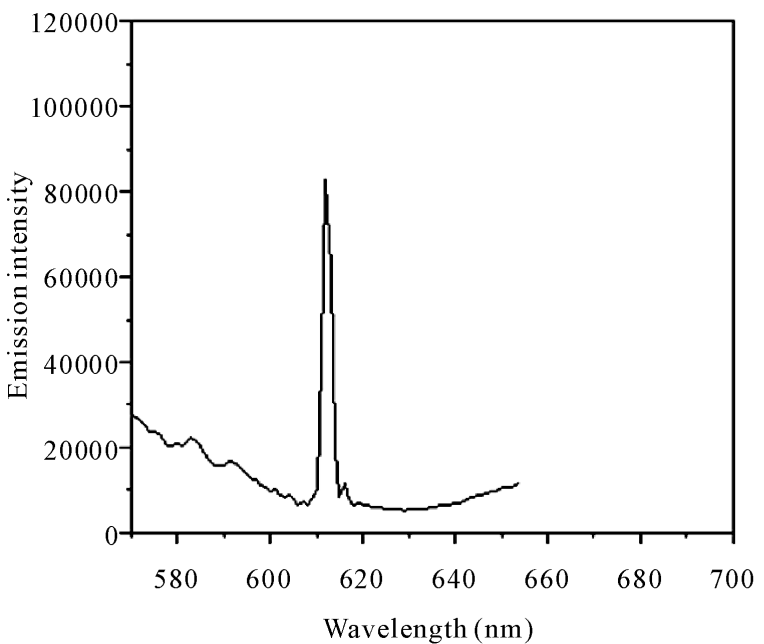

(c)

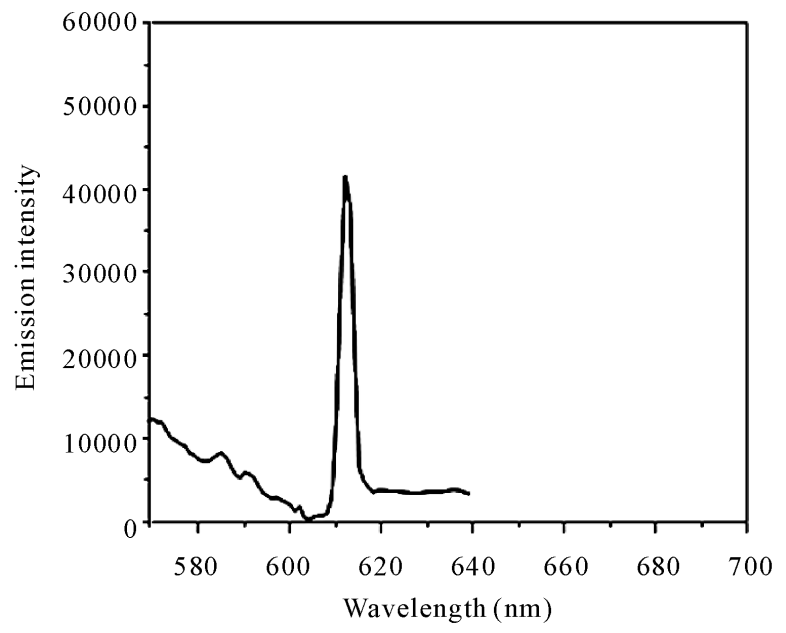

(b)

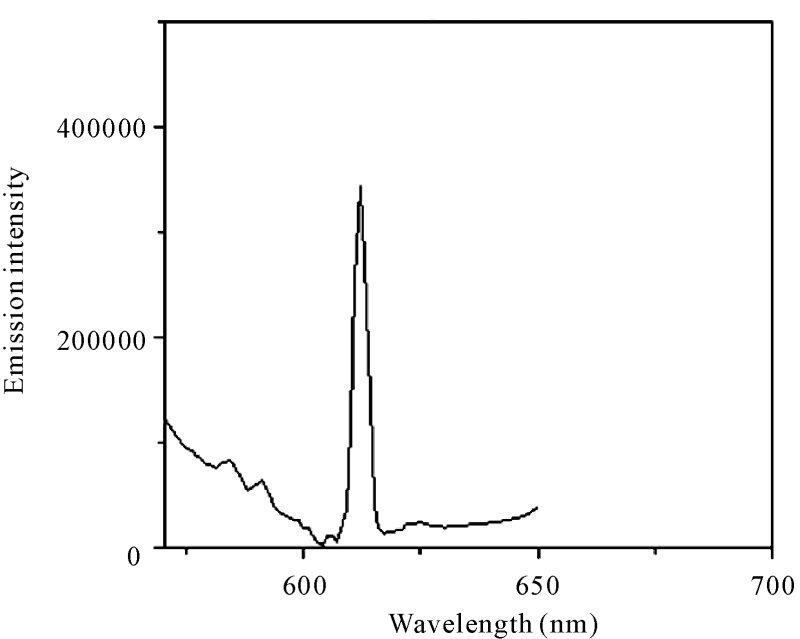

(d)

Figure 5. Fluorescence spectra of complex $L B$ films emission spectra of $\operatorname{Eu}(\operatorname{PAM})_{3} \mathrm{~N}_{18}(a), \operatorname{Eu}(\operatorname{PAM})_{3} \mathrm{~N}_{14}(\mathrm{~b}), \operatorname{Eu}$ $(\mathrm{PAM})_{3} \mathrm{~N}_{10}(\mathrm{c}), \operatorname{Eu}(\mathrm{PAM})_{3} \mathrm{~N}_{6}(\mathrm{~d})$.

Table 4. Complex emission spectra.

\begin{tabular}{cccccc}
\hline Complexes & Layers number & ${ }^{5} \mathrm{D}_{0} \rightarrow{ }^{7} \mathrm{~F}_{0}$ & ${ }^{5} \mathrm{D}_{0} \rightarrow{ }^{7} \mathrm{~F}_{1}$ & ${ }^{5} \mathrm{D}_{0} \rightarrow{ }^{7} \mathrm{~F}_{2}$ & Monochromacity factor \\
\hline Eu(PMA) ${ }_{3} \mathrm{~N}_{18}$ & 100 & 582 & 591 & 612 & 3.85 \\
$\mathrm{Eu}(\mathrm{PMA})_{3} \mathrm{~N}_{14}$ & 100 & 580 & 591 & 612 & 4.23 \\
$\mathrm{Eu}(\mathrm{PMA})_{3} \mathrm{~N}_{10}$ & 100 & 584 & 591 & 612 & 6.18 \\
$\mathrm{Eu}(\mathrm{PMA})_{3} \mathrm{~N}_{6}$ & 100 & 579 & 591 & 612 & 5.24 \\
\hline
\end{tabular}

states, subsequent intersystem crossing of the ligands to their triplet states, and the energy transfer from the triplet state of the ligand to ${ }^{5} \mathrm{D}_{J}$ manifold of the $\mathrm{Eu}^{3+}$ ion, following by intenal conversion to the emitting ${ }^{5} \mathrm{D}_{0}$ state; finally the $\mathrm{Eu}^{3+}$ ion emits when the $4 \mathrm{f}$ electrons undergo a transition from the excited state of ${ }^{5} \mathrm{D}_{0}$ to the ground state [37]. Moreover, the electron transition from the higher excited states, such as ${ }^{5} \mathrm{D}_{3}\left(24800 \mathrm{~cm}^{-1}\right),{ }^{5} \mathrm{D}_{2}$ $\left(21200 \mathrm{~cm}^{-1}\right)$, and ${ }^{5} \mathrm{D}_{1}\left(19000 \mathrm{~cm}^{-1}\right)$, to ${ }^{5} \mathrm{D}_{0}\left(17500 \mathrm{~cm}^{-1}\right)$ becomes feasible by internal conversion, and most of the photophysical processes take place in this orbital. Consequently, most europium complexes give rise to 
typical emission bands at 581, 593, 614, 654, and 702 $\mathrm{nm}$ corresponding to the deactivation of the excited state ${ }^{5} \mathrm{D}_{0}$ to the ground states ${ }^{7} \mathrm{~F}_{J}(J=0-4)$. Therefore, matching the energy levels of the triplet state of the ligands to ${ }^{5} \mathrm{D}_{0}$ of $\mathrm{Eu}^{3+}$ is one of the key factors that affect the luminescent properties of the europium complexes.

Based on the above experimental results, the triplet energy level of PAM (20 $\left.200 \mathrm{~cm}^{-1}\right)$ is obviously higher than the ${ }^{5} \mathrm{D}_{0}$ level $\left(17500 \mathrm{~cm}^{-1}\right)$ of $\mathrm{Eu}^{3+}$, and its energy gap $\Delta E\left({ }^{3} \pi \pi^{*}-{ }^{5} \mathrm{D}_{0}\right)$ between ligand and metal-centered levels is too high to allow an effective back energy transfer. According to Latva's empirical rule [27,38], an optimal ligand-to-metal energy transfer process for $\mathrm{Eu}^{3+}$ needs $\Delta E\left({ }^{3} \pi \pi^{*}-{ }^{5} \mathrm{D}_{0}\right)>2500 \mathrm{~cm}^{-1}$ and hence the energy transfer process is effective for these complexes.

\subsection{Surface Topography of Europium Complexes Monolayer}

Monolayer assembles of these complexes were fabricated by the LB method and transferred onto substrate with a vertical lifting technique. Monolayer morphology of these amphiphilic Eu(III) complexes with different long chains has been investigated by AFM method, that showed that the structure for the monolayers of Eu complexes was closely related to the length of long chains. Qian et al investigated the monolayer assemblies of some europium, complexes with the $\hat{a}$-diketonate ligand thienyltrifluoroacetone and concluded that the closely packed structures of the complexes have some influences on the emissions of the lanthanoid ions, especially for the $\mathrm{Eu}$ and samarium complexes [22]. Therefore, we try to insight the relationship between their arrangement and fluorescence properties of europium complexes.

The AFM images of Eu complexes monolayer were shown in Figure 6. The aggregation of $\mathrm{Eu}(\mathrm{PMA})_{3} \mathrm{~N}_{6} \mathrm{LB}$ films were flat and smooth (Figure 6(a)), having directionality and orientation without deficiency. Explained from molecular level, we thought that molecules arranging regularly in LB films and the distance between molecules in LB films became shorter, which made the $\pi-\pi *$ interaction strengthened. It illustrated that the surface pressure in LB formation procedure was supplied a comfortable force which made the film resist deformation to form stable monolayer. In order to observe surface aggregations in LB films, AFM images were amplified to 500 $\mathrm{nm} \times 500 \mathrm{~nm}$ (Figure 6(b)), in which we could see loose surface topography in the $\mathrm{Eu}(\mathrm{PMA})_{3} \mathrm{~N}_{6}$ film. The molecules arrangement was supposed in a loose state, in which there is a little distance between molecules.

In the case of $\mathrm{Eu}(\mathrm{PMA})_{3} \mathrm{~N}_{10}, \mathrm{Eu}(\mathrm{PMA})_{3} \mathrm{~N}_{14}$ and $\mathrm{Eu}$ (PMA) ${ }_{3} \mathrm{~N}_{18}$, "Hole coral" was observed in the Eu(PMA) $)_{3}$ $\mathrm{N}_{10}$ film AMF image (Figures 7(a), (b)). The probable orientation of $\mathrm{Eu}(\mathrm{PMA})_{3} \mathrm{~N}_{10}$ was that there are some overlapping parts among $\mathrm{Eu}(\mathrm{PMA})_{3} \mathrm{~N}_{10}$ molecules.

We also could find the aggregates of the $\mathrm{Eu}(\mathrm{PMA})_{3} \mathrm{~N}_{14}$ films and the $\mathrm{Eu}(\mathrm{PMA})_{3} \mathrm{~N}_{18}$ films were packing neatly and showed "columnar shape" and "tetragonal shape" showing more condense structure in Figures 8(a), (b) and Figures 9(a), (b), in which there are more overlapping parts among molecules. It leads the part energy absorbed to transfer to ligands instead of transferring to centre ion. Arrangement way in the $\operatorname{Eu}(\mathrm{PMA})_{3} \mathrm{~N}_{6}$ film and in the $\mathrm{Eu}(\mathrm{PMA})_{3} \mathrm{~N}_{10}$ film were packing more loosen

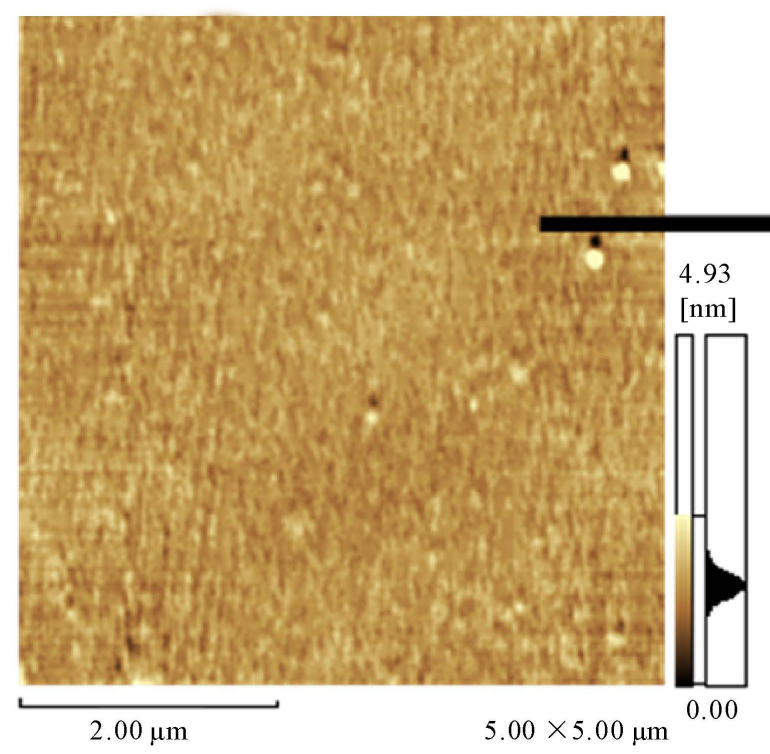

(a)

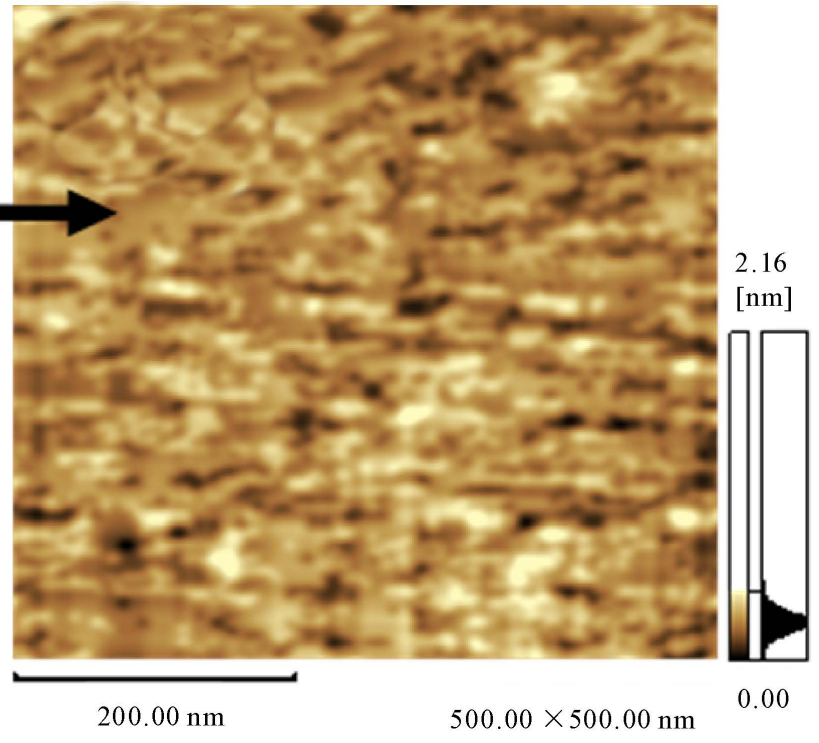

(b)

Figure 6. AFM images: (a) Monolayer of $\operatorname{Eu}(P M A)_{3} N_{6}$, (b) Amplified monolayer of $\operatorname{Eu}(\operatorname{PMA})_{3} \mathrm{~N}_{6}$. 


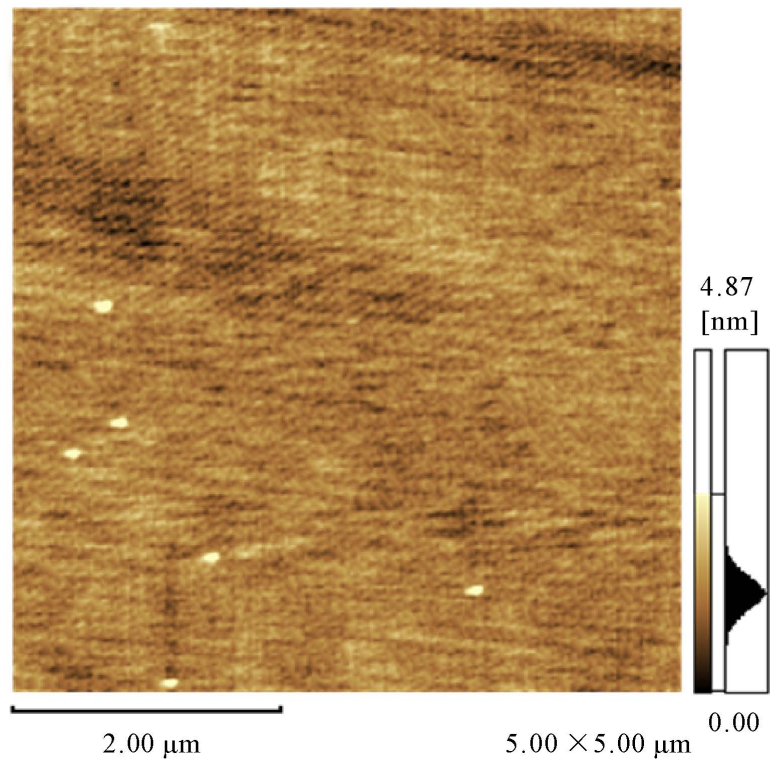

(a)

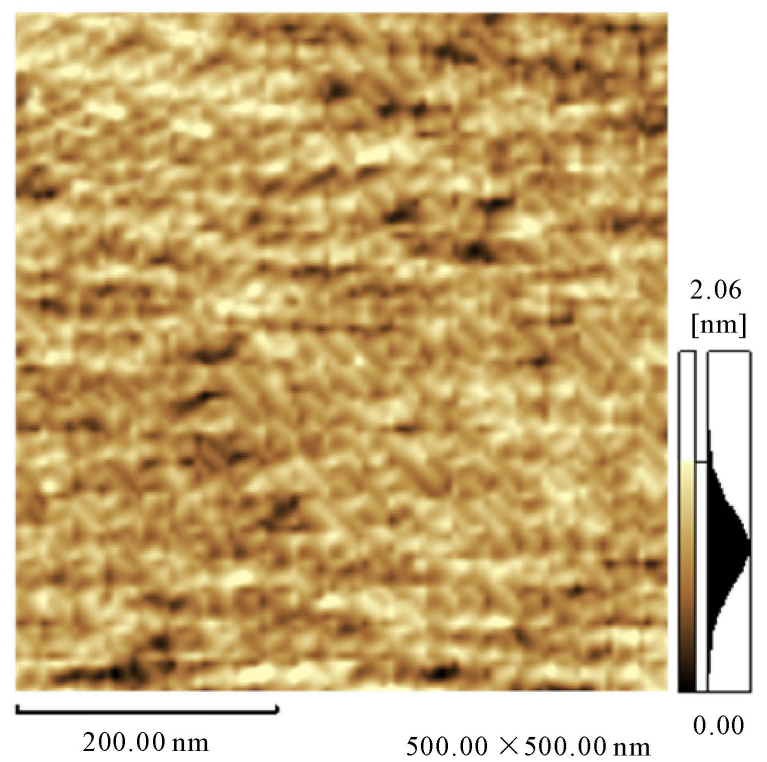

(b)

Figure 7. AFM pictures: (a) Monolayer of $\operatorname{Eu}(\mathrm{PMA})_{3} \mathrm{~N}_{10}$, (b) Amplified monolayer of $\operatorname{Eu}(\operatorname{PMA})_{3} \mathrm{~N}_{10}$.

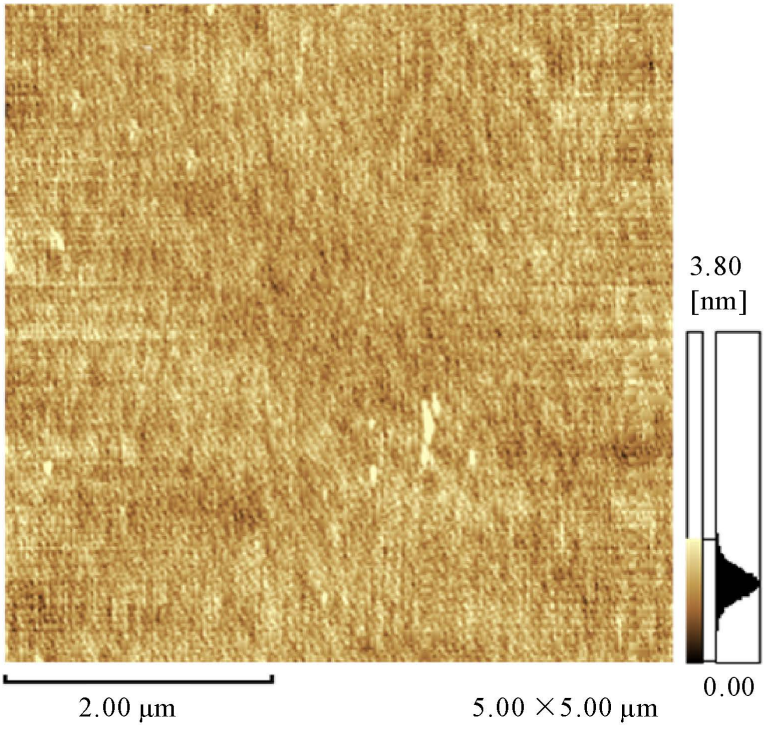

(a)

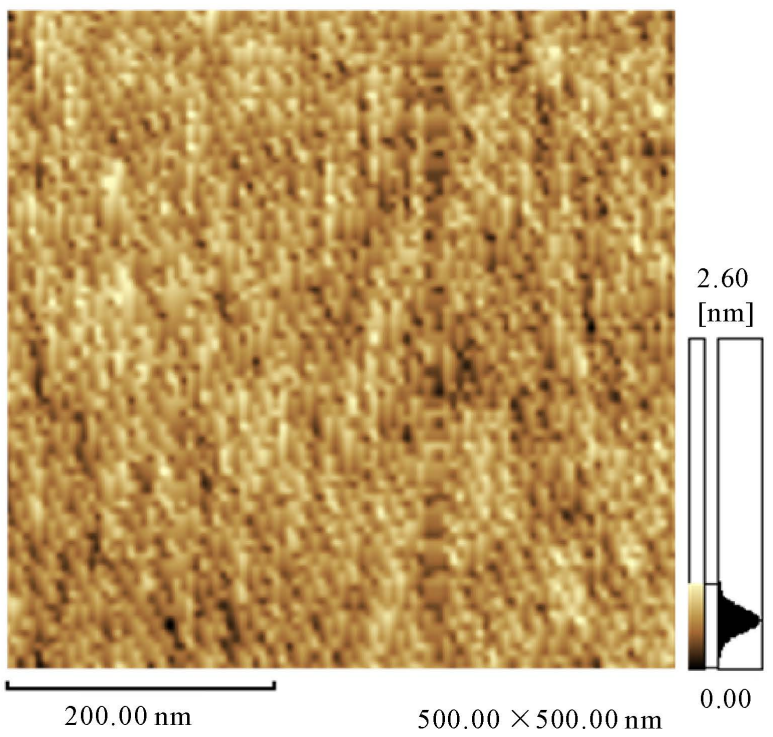

(b)

Figure 8. AFM images: (a) Monolayer of $\mathrm{Eu}(\mathrm{PMA})_{3} \mathrm{~N}_{14}$, (b) Amplified monolayer of $\mathrm{Eu}(\mathrm{PMA})_{3} \mathrm{~N}_{14}$.

than that of other films. We thought that energy obtained from certain wavelength light could transfer more easily from ligands to center ion in the $\mathrm{Eu}(\mathrm{PMA})_{3} \mathrm{~N}_{6} \mathrm{LB}$ films and in the $\operatorname{Eu}(\mathrm{PMA})_{3} \mathrm{~N}_{10}$ LB films which led to higher monochromaticity. It was obvious that monochromaticity had some special relationship with the arrangement of molecular in film. At the same time, we can conclude that if we arrange the orientation of molecule in proper certain way with LB technology, energy transferring from ligand to centre ion can be efficiently achieved and strong luminescent intensity and $\mathrm{Eu}(\mathrm{III})$ center ion emis- sion monochromaticity be obtained. It is interesting that the molecular with looser arrangement in LB films has better monochromacity, which illustrated that energy might transferred more easily in loosen structure films.

\section{Conclusions}

A series of new amphiphilic Eu(III) complexes were synthesized and were fabricated into ordered LB films. All of these amphiphilic europium(III) complexes could form stable Langmuir film at air/water interface and 


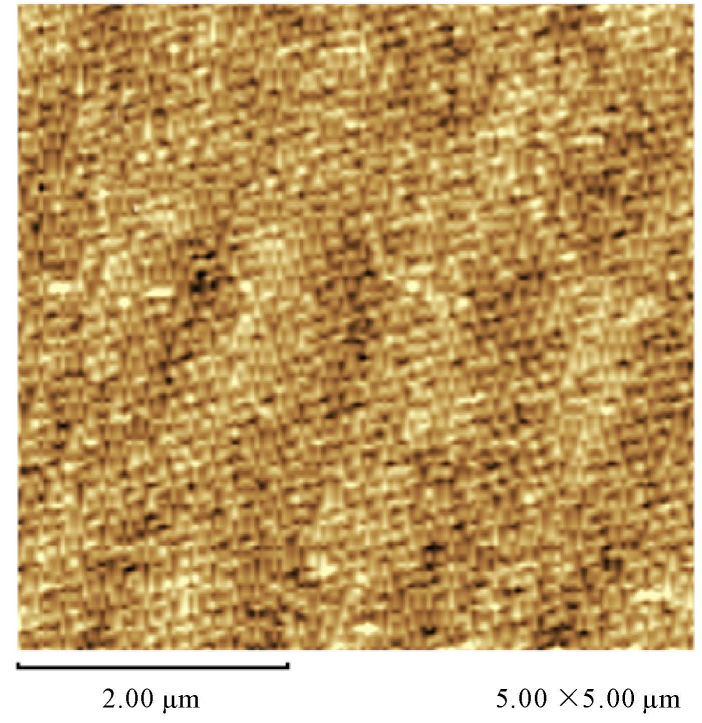

(a)

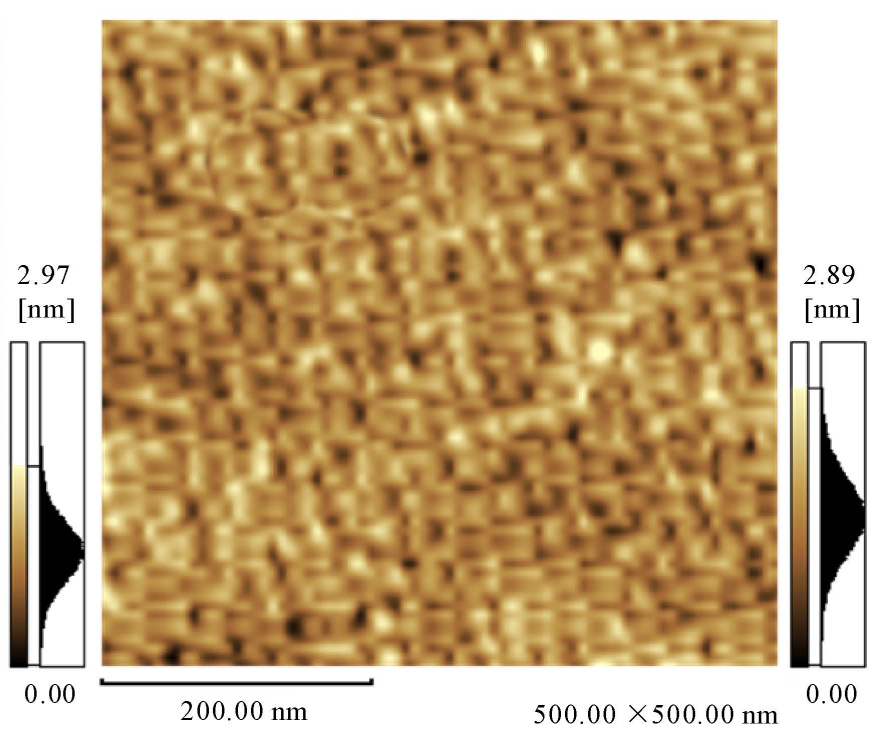

(b)

Figure 9. AFM pictures: (a) Monolayer of $\operatorname{Eu}(\mathrm{PMA})_{3} \mathrm{~N}_{18}$, (b) Amplified monolayer of $\operatorname{Eu}(\mathrm{PMA})_{3} \mathrm{~N}_{18}$.

could be transferred onto hydrophilic quartz and mica substrates. In order to investigate relation between fluorescence properties and the arrangement of molecular in LB films, surface topography of monolayer and fluorescence properties of LB films were investigated by fluorescence spectroscopy and atomic force microscopy (AFM), respectively. Results showed that order structure of LB films could give strong $\mathrm{Eu}^{3+}$ characteristic emission spectra.

$\mathrm{Eu}(\mathrm{PMA})_{3} \mathrm{~N}_{6}$ and $\mathrm{Eu}(\mathrm{PMA})_{3} \mathrm{~N}_{10}$ gave higher monochromacity factor than that of other complexes films because of the loosen structure of LB films. We thought that the loosen structure of LB films might transfer energy from ligands to center ion more easily, which lead to better monochromacity factors.

\section{Acknowledgments}

This work is supported by the National Nature Science Fund of China (20973157), the Found for Outstanding Younger Scholar of Henan Province (074100510015), the fund for development of Zhengzhou (094SGZG23056).

\section{References}

[1] Y. Matsuda, S. Makishima and S. Shinoya, "Intramolecular Engergy Transfer in EuropiumChelatesDu to Excitation of the Triplet State," Bulletin of the Chemical Society of Japan, Vol. 41, 1968, pp. 1513-1518. doi:10.1246/bcsj.41.1513

[2] G. E. Buono-Core, H. Li and B. Marciniak, "Quenching of Excited States by Lanthanide Ions and Chelates in Solution," Coordination Chemistry Reviews, Vol. 99, March
1990, pp. 55-87. doi:10.1016/0010-8545(90)80060-7

[3] N. Filipescu, M. R. Kagan, N. McAvoy and F. A. Serafin, "Fluorescent Properties of Rare Earth Chelates in Vinylic Hosts," Nature, Vol. 196, 1962, pp. 467-468. doi: $10.1038 / 196467 \mathrm{a} 0$

[4] P. P. Sun, J. P. Duan, J. J. Lih and C. H. Cheng, "Synthesis of New Europium Complexes and Their Application in Electroluminescent Devices," Advanced Functional Materials, Vol. 13, No. 9, September 2003, pp. 683-691. doi:10.1002/adfm. 200304378

[5] N. A. H. Male, O. V. Salata and V. Christou, "Enhanced Electroluminescent Efficiency from Spin-Coated Europium(III) Organic Light-Emitting Device," Synthetic Metals, Vol. 126, No. 1, January 2002, pp. 7-10. doi:10.1016/S0379-6779(01)00373-3

[6] Y. Amao, I. Okura and T. Miyashita, "Optical Oxygen Sensing Based on the Luminescence Quenching of Europium(III) Complex Immobilized in Fluoropolymer Film," Bulletin of the Chemical Society of Japan, Vol. 73, No. 12, 2000, pp. 2663-2668. doi:10.1246/bcsj.73.2663

[7] B. B. J. Basu and N. Vasantharajan, "Temperature Dependence of the Luminescence Lifetime of a Europium Complex Immobilized in Different Polymer Matrices," Journal of Luminescence, Vol. 128, No. 10, October 2008, pp. 1701-1708. doi:10.1016/j.jlumin.2008.03.024

[8] D. P. Arnold, D. Manno, G. Micocci, A. Serra, A. Tepore and L. Valli, "Porphyrin Dimers Linked by a Conjugated Alkyne Bridge: Novel Moieties for the Growth of Langmuir - Blodgett Films and Their Applications in Gas Sensors," Langmuir, Vol. 13, No. 22, October 1997, pp 5951-5956. doi:10.1021/1a970487y

[9] H. Kuhn and D. Mobius, "Systeme aus monomolekularen Schichten-Zusammenbau und physikalisch-chemisches Verhalten," Angewandte Chemie, Vol. 83, No. 17-18, 
September 1971, pp. 672-690. doi:10.1002/ange.19710831705

[10] L. Zhang, H. G. Liu, S. Z. Kang, Y. D. Mu, D. J. Qian, Y. I. Lee and X. S. Feng, "Novel Luminescent LangmuirBlodgett Films of Europium Complex Embedded in Titania Matrix," Thin Solid Films, Vol. 491, No. 1-2, 22 November 2005, pp. 217-220.

[11] G. Zou, Y. Z. Zhang and P. S. He, "Fabrication and Characterization of Langmuir - Blodgett Films Based on Rare Earth $\beta$-Diketonate Complexes," Thin Solid Films, Vol. 468, No. 1-2, December 2004, pp. 268-272.

[12] G. L. Zhong, Y. H. Wang, C. K. Wang, B. Y. Pu, Y. Feng, K. Z. Yang and J. I. Jin, "Assemblies, Characterization, and Luminescent Enhancement of Organized Molecular Films Based on Rare Earth Complexes," Journal of Luminescence, Vol. 99, No. 3, October 2002, pp. 213-222. doi:10.1016/S0022-2313(02)00340-X

[13] R. J. Zhang and K. Z. Yang, "Investigation on Fluorescence Stability of a Series of Atypical Amphiphilic $\beta$-Diketone Rare Earth Complex LB Films," Acta Chimica Sinica, Vol. 58, No. 7, 2000, pp. 748-752.

[14] R. J. Zhang and K. Z. Yang, "Investigation on Monolayers and Langmuir-Blodgett Films of Atypical Amphiphilic Terbium Complexes," Thin Solid Films, Vol. 371, No. 1-2, August 2000, pp. 235-241.

[15] D. J. Qian, H. Nakahara, K. Fukuda and K. Z. Yang, "Emission Behavior of Lanthanoid Complexes in Monolayer Assemblies," Langmuir, Vol. 11, No. 11, 1995, pp. 4491-4494. doi:10.1021/la00011a051

[16] X. Gao, H. G. Liu, Y. Zhang, J. Ren and K. Z. Yang, "Crystallization in Europium Complex Monolayers on a Composite Subphase," Thin Solid Films, Vol. 284-285, 15 September 1996, pp. 39-42.

[17] M. Jiang and M. H. Liu, "A Photoluminescent Switch Based on the Hybrid Organized Molecular Films of decatung-Steuropate and Some Amphiphiles," Journal of Colloid and Interface Science, Vol. 316, No. 1, December 2007, pp. 100-106. doi:10.1016/j.jcis.2007.07.081

[18] M. Jiang, X. D. Zhai and M. H. Liu, "Fabrication and Photoluminescence of Hybrid Organized Molecular Films of a Series of Gemini Amphiphiles and Europium(III)Containing Polyoxometalate," Langmuir, Vol. 21, No. 24, 2005, pp. 11128-11135. doi:10.1021/la051855y

[19] W. Li, H. L. Li and L. X. Wu, "Structure Characterization of Dimethyldioctadecylammo-Nium-Encaspsulated Terbium-Substituted Heteropolyoxotugates in Solid LB Films and Solvent-Casting Films," Colloids and Surfaces A: Physicochemical and Engineering Aspects, Vol. 272, No. 3, 2006, pp. 176-181. doi:10.1016/j.colsurfa.2005.07.021

[20] K. Z. Wang, L. H. Gao and C. H. Hang, "Optical Properties of the Highly Ordered Langmuir-Blodgett film of a Strongly Luminescent Eu(III) Complex," Journal of Photochemistry and Photobiology A: Chemistry, Vol. 156, No. 1-3, 2003, pp. 39-43. doi:10.1016/S1010-6030(02)00437-9

[21] M. Mitsuishi, S. Kikuchi, T. Miyashita and Y. Amao, "Characterization of an Ultrathin Polymer Optode and Its
Application to Temperature Sensors Based Luminescent Europium Complexes," Journal of Materials Chemistry Vol. 13, 2003, pp. 2875-2879. doi:10.1039/b307309b

[22] D. J. Qian, H. Nakahara, K. Fukuda and K. Z. Yang, "Monolayer Assemblies of Long-Chain Complex Containing Rare-Earth Metal: N,N-Distearyl-dimethylammonium Tetra (4,4,4-trifluoro-1-(2-thienyl)-1,3-butanediono) Europate(III)," Chemical Letter, Vol. 24, No. 3, 1995, p. 175. doi:10.1246/cl.1995.175

[23] W. Qi, H. L. Li and L. Wu, "A Novel, Luminescent, Silica-Sol-Gel Hybrid Based on Surfactant-Encapsulated Polyoxometalates," Advanced Materials, Vol. 19, No. 15, August 2007, pp. 1983-1987.

doi:10.1002/adma.200602430

[24] L. Huang, K. Z. Wang, C. H. Huang, D. Q. Gao and L. P. Jin, "Synthetic and Electroluminescent Properties of Two Novel Europium Complexes with Benzimidazole Derivatives as Second Ligands," Synthetic Metals, Vol. 128, No. 3, 2002, pp. 241-245.

[25] D. Q. Gao, Z. Q. Bian, K. Z. Wang, L. P. Jin and C. H. Huang, "Synthesis and Electroluminescence Properties of an Organic Europium Complex," Journal of Alloys and Compounds, Vol. 358, No. 1-2, 2003, 188-192. doi:10.1016/S0925-8388(03)00048-3

[26] J. J. Ding, H. F. Jiu, J. Bao, J. C. Lu, W. R. Gui, Q. J. Zhang and C. Gao, "Combinatorial Study of Cofluorescence of Rare Earth Organic Complexes Doped in the Poly (Methyl Methacrylate) Matrix," Journal of Combinatorial Chemistry, Vol. 7, No. 1, 2005, pp. 69-72. doi:10.1021/cc049902c

[27] C. Hiort, P. Lincoln and B. Norden, "DNA Binding of .DELTA.- and .LAMBDA.-[Ru(phen)2DPPZ]2+," Journal of the American Chemical Society, Vol. 115, No. 9, 1993, pp. 3448-3454. doi:10.1021/ja00062a007

[28] E. A. Steck and A. R. Day, "Reactions of Phenanthraquinone and Retenequinone with Aldehydes and Ammonium Acetate in Acetic Acid Solution," Journal of the American Chemical Society, Vol. 65, No. 3, 1943, pp. 452-456. doi:10.1021/ja01243a043

[29] H. B. Zhao, J. H. Ning, J. Cai, J. H. Zhou, N. Zhou, S. M. Peng, "Studies on the Synthesis of a Series of Alkoxybenzaldehyde," Chemistry Research, Vol. 12, No. 1, 2001, p. 19.

[30] M. S. Gibson, "Hydrazones III, Intramolecular 1,3-Dipolar Additions Involving Nitro- and Carbonyl Groups," Tetrahedron, Vol. 18, No. 12, 1962, pp. 13771380. doi:10.1016/S0040-4020(01)99292-0

[31] W. Yang, Q. Y. Ou, Z. L. Mo, X. L. Teng, M. Chen, J. Z. Gao, L. Yuan and J. W. Kang, "Determination of Trace Europium Based on New Ternary Fluorimetric Enhancement System of Europium(III) with Thenoyltrifluoroacetone and Trisalicylicamido Triethylamine," Analyst, Vol. 123, 1998, pp. 1745-1748. doi:10.1039/a802278j

[32] G. Blasse and B. C. Grambmaier, "Luminescent Materials," Springer, Berlin, 1993.

[33] D. J. Qian, K. Z. Yang, H. Nakahara and K. Fukuda, "Monolayers of Europium Complexes with Different Long Chains and â-Diketonate Ligands and Their Emis- 
sion Properties in Langmuir-Blodgett Films," Langmuir, Vol. 13, No. 22, 1997, pp. 5925-5932.

[34] S. Biju, D. B. Ambili Raj, M. L. P. Reddy and B. M. Kariuki, "Synthesis, Crystal Structure, and Luminescent Properties of Novel $\mathrm{Eu}^{3+}$ Heterocyclic $\beta$-Diketonate Complexes with Bidentate Nitrogen Donors," Inorganic Chemistry, Vol. 45, No. 26, 2006, pp. 10651-10660. doi:10.1021/ic061425a

[35] F. L Zhang, Y. H. Hou, C. X. Du and Y. J. Wu, "Synthesis, Structures, Photo- and Electro-Luminescent Properties of Novel Oxadiazole-Functionlized Europium(III) Benzamide Complexes," Dalton Transactions, No. 36, 2009, pp. 7359-7367. doi:10.1039/b906470b

[36] X. Yu and Q. Su, "Photoacoustic and Luminescence Properties Study on Energy Transfer Andrelaxation Processes of Tb(III) Complexes with Benzoic Acid," Journal of Photochemistry and Photobiology A: Chemistry, Vol. 155, No. 1-3, 2003, pp. 73-78. doi:10.1016/S1010-6030(02)00362-3

[37] M. Shi, F. Y. Li, T. Yi, D. Q. Zhang, H. M. Hu and C. H. Huang, "Tuning the Triplet Energy Levels of Pyrazolone Ligands to Match the ${ }^{5} \mathrm{D}_{0}$ Level of Europium(III)," Inorganic Chemistry, Vol. 44, No. 24, 2005, pp. 8929-8936. doi:10.1021/ic050844p

[38] M. Latva, H. Takalo, V. M. Mukkala, C. Matachescu, J. C. Rodriguez-Ubis and J. Kanakare, "Correlation between the Lowest Triplet State Energy Level of the Ligand and Lanthanide(III) Luminescence Quantum Yield," Journal of Luminescence, Vol. 75, No. 2, September 1997, pp. 149-169.

doi:10.1016/S0022-2313(97)00113-0 